\title{
Competition, Income Distribution, and the Middle Class: An Experimental Study
}

\author{
Bernhard Kittel, ${ }^{1}$ Fabian Paetzel, ${ }^{2}$ and Stefan Traub ${ }^{2}$ \\ ${ }^{1}$ Department of Economic Sociology and FOR 2104, University of Vienna, 1090 Vienna, Austria \\ ${ }^{2}$ Department of Economics and FOR 2104, Helmut-Schmidt-University, 22043 Hamburg, Germany \\ Correspondence should be addressed to Bernhard Kittel; bernhard.kittel@univie.ac.at
}

Received 5 December 2014; Revised 28 January 2015; Accepted 17 February 2015

Academic Editor: Klarita Gërxhani

Copyright (C) 2015 Bernhard Kittel et al. This is an open access article distributed under the Creative Commons Attribution License, which permits unrestricted use, distribution, and reproduction in any medium, provided the original work is properly cited.

\begin{abstract}
We study the effect of competition on income distribution by means of a two-stage experiment. Heterogeneous endowments are earned in a contest, followed by a surplus-sharing task. The experimental test confirms our initial hypothesis that the existence of a middle class is as effective as institutional hurdles in limiting the power of the less able in order to protect the more able players from being expropriated. Furthermore, majoritarian voting with a middle class involves fewer bargaining impasses than granting veto rights to the more able players and, therefore, is more efficient.
\end{abstract}

\section{Introduction}

In recent years, public awareness of an increasingly lopsided distribution of income and wealth in Western countries has strongly increased [1]. Most OECD countries have witnessed growing inequality over the past 20 years [2]. In particular, the gap between the bottom and the top deciles of the household income distribution has risen dramatically. The decile ratio currently amounts to about $1: 15$ in the US and 1:9 in the OECD-34, and even in a Nordic welfare state like Sweden it is close to $1: 6$. Given the fact that the typical OECD income distribution is right-skewed [3], it does not come as a surprise that income tax progression is much higher in the US than in Sweden [4].

Observers diagnose the formation, as well as deliberate establishment, of a winner-take-all society in which the middle class is gradually eroded [5-7]. A few superstars, which may (or may not) be the most able practitioners in a particular area, receive all the profit while the others' efforts are in vain (e.g., [8-10]). Some commentators expect this development to result in increasing societal division, distributive struggle, and violent conflict [11].

On the other hand, the fall of communist regimes in 1989 has demonstrated the crippling effects of excessive egalitarianism on economic efficiency and growth $[12,13]$. Societies, or groups, thus need to strike a balance between both excessive inequality and excessive equality. In principle, either an institutional or a structural condition is sufficient to protect a society against excesses from both sides. On the one hand, institutional rules of collective decision-making giving veto power to all stakeholders $[14,15]$ enforce a consensual decision and thereby make the distributional struggle an issue of explicit negotiation. On the other hand, the existence of a neutral but opportunistic middle class serves as a buffer between the upper and the lower classes because they fear expropriation from both sides and will thus side with the weaker group in case of conflict [16-18]. Moreover, not being the main target of redistribution, members of the middle class will let their decisions be guided more by moral values such as justice norms than the other two socioeconomic groups [19-21].

The two conditions, however, differ with respect to their decision efficiency. Although the unanimity rule minimizes external costs due to the inclusion of all members of the society, it also allows every member to hold up the decision until the outcome satisfactorily represents its particular interests. For this reason, this arrangement is almost inexistent at 
the level of nation states and is notorious for its detrimental effects in the security council of the United Nations. Because of its crippling implications, the unanimity rule has been replaced by qualified majority for many policy areas in the European Council by the Lisbon Treaty in 2007. In contrast, the position-based interests of the middle class limit the costs burdened upon the minority because its members will shift sides as soon as demands on the minority become expropriatory. The existence of a middle class thus quasiautomatically corrects for both excessive inequality and equality without generating the hold-up effect of an institutional rule.

In this paper, we experimentally test the composite hypothesis following from this argument that, in democratic and competitive organizations, both the existence of a middle class and institutional hurdles can protect the most able organization members from the demand of the least able for excessive income distribution policies (Protection Hypothesis); yet, setting up institutional hurdles is inferior to relying on a middle class as institutional hurdles involve efficiency losses due to bargaining impasses (Efficiency Hypothesis).

In our experiment, we directly test whether a neutral middle class is as effective as an institutional rule to avoid excessive expropriation or extremely low redistribution. The second goal of the paper is to check if the existence of a middle class leads to higher efficiency than institutional hurdles.

The experiment was composed of two consecutive tasks. During the first task, subjects took part in a multiple-prize rank-order contest that involved a simple cognitive ability task. The contest rewarded effort by assigning the first prize to the most able subject, the second prize to the second most able subject, and so on. Following Moldovanu and Sela [22], the contest ensured that more able subjects should expend more effort in order to win it. Hereby, we focus on the impact of the skewness of the prize scheme on effort and its interaction with ex-post income distribution. During the second task players first deliberated on sharing a surplus (using a group chat). As soon as the deliberation time had elapsed, they simultaneously and anonymously made their binding proposals for a distribution parameter. The proposal that achieved the quorum was played out and the surplus shares were added to the prize money won in the contest. If a group missed the quorum, the players received only their prizes.

We find that the Protection Hypothesis is clearly supported by our data. The existence of a neutral middle class is as effective as institutional hurdles. The Efficiency Hypothesis is also supported. Institutional hurdles come at the costs of significantly less efficiency in terms of higher default rates. The corroboration of both hypotheses allows us to give a clear recommendation for the rich. The rich should brace against the erosion of the middle class because the middle class is the efficient protection of the rich.

The rest of the paper is organized as follows. Section 2 links our paper to the literature. Section 3 introduces the theoretical framework of our experiment and derives testable hypotheses. Section 4 explains how the models were transferred into the experimental lab. Section 5 reports the results of the experiment. Section 6 discusses the results and concludes the paper.

\section{Literature Review}

If we assume that subjects solely follow self-interest and that self-interest is directly expressed in a social contract with a corresponding level of redistribution, we find ourself in the world of the median voter theorem [23]. Following this theory, an increasing skewness must result in larger pressure for equalization because the median voter's income declines and hence her interest in redistribution increases [23, 24]. Disregarding the possibility of revolutionary redistribution (tax rates exceeding one), the most extreme form of equalization within a society is to implement, by means of collective decision, a measure which results in equal payoffs. This result, however, is likely to generate socially inefficient outcomes because it undermines the willingness of the more able to expend effort [25].

Our paper contributes to the growing literature analyzing why the rich do not get expropriated. Besides the above-mentioned protection through institutional hurdles or the existence of a neutral middle class, another stream in the literature stresses different explanations why the poor median voter does not necessarily follow the median voter's prediction. The "prospects of upward mobility" hypothesis [26] brings forward the argument that some voters who have an income below the mean expect that their future income will be above the mean. The expectation of these voters works against votes for high levels of redistribution. Roemer [27] and Roemer and Lee [28] show that voting about redistribution is also affected by religion and race. The more fragmented the population is with regard to both dimensions, the lower is the willingness to redistribute. Alesina and Angeletos [13] and Fong [29] show that if the poor believe that the rich are rich because they had invested high efforts and have high abilities, the pressure for redistribution is low. According to extensive empirical and experimental literature, people tend to accept some amount of inequality if it can be attributed to individual effort and ability (e.g., [30-35]). Klor and Shayo [36] find that if the poor identify themselves with the nation (rich and poor) the poor do not want to harm members of the nation and therefore do not expropriate the rich. Moreover, Glaeser et al. [18] highlight that, beyond being protected from expropriation through institutions which are maintained to enforce low levels of redistribution, the betteroff are able to manipulate institutions to their own profit. Our paper adds an additional explanation of why the poor cannot enforce high levels of redistribution. We argue that the middle class acts as an uninvolved spectator not affected by redistribution that does not have an interest in excesses from either side.

We contribute to a recent wave of research investigating voting on redistribution. This literature sheds some light on the voting decision by using experiments. The main methodological advantage of using experiments is that it allows us to detect how preferences affect the voting-decision. A stylized fact generated by this literature is that voters are willing to sacrifice their own payoffs in order to achieve a more equal payoff distribution, which has been explained by social preferences or social identity. Tyran and Sausgruber [37] reported supporting evidence for inequity theory [38] 
but emphasized the importance of being pivotal for voting on redistribution. Similarly, Höchtl et al. [39] showed that for empirically plausible cases inequality-averse voters may not matter for redistribution outcomes. Moreover, they did not observe efficiency-loving voters. Bolton and Ockenfels [40] investigated the trade-off between equity and efficiency motives in a voting game with three voters. They found that twice as many voters were willing to give up their own payoff in favor of an equal distribution as compared to a more efficient but unequal distribution. Messer et al. [41] studied the impact of majority voting on the provision of a public good. They detected substantial concerns for efficiency in the subjects' behavior but found little support for inequality aversion and maximin preferences. Paetzel et al. [42] investigated whether voters would be willing to sacrifice their own payoff in order to implement not only an efficiency-increasing but also an inequality-increasing reform. This case can be thought of as the reverse of voting on efficiency-reducing but inequality-decreasing redistribution. They showed that efficiency preferences of potential reformlosers outweighed the inequality aversion of reform-gainers. Klor and Shayo [36] reported a trade-off between socialidentity concerns and payoffs maximization: a subset of their sample systematically deviated from monetary payoff maximization towards a tax rate benefiting their group. Such deviations can neither be explained by efficiency concerns nor by inequality aversion.

Recently, Balafoutas et al. [43] reported on an experiment similar to ours (heterogenous initial endowments, quiz versus random assignment, majority vote, and neutral middle player), which generated a number of interesting results. For example, the players with the highest and the lowest endowments were mainly driven by material selfinterest. Low-endowment players, however, signalled their willingness to cooperate by increasing their contributions if the redistribution rate was determined by majority vote. ${ }^{1}$ Our experiment differs in various important respects: the size of the pie to be redistributed is exogenously given, our game involves a communication phase before voting on the tax, and we vary both the initial distribution of endowments and the institutional background in terms of the quorum.

A bit against the trend, Esarey et al. [44] and Durante et al. [45] still found redistribution to be strongly related to the self-interest of voters. Durante et al. [45] showed that support for redistribution vanishes if taxation was associated with costs and deadweight losses and if participants earned their incomes in a real effort task.

\section{Theoretical Framework}

In this section, we introduce the theoretical framework of our experiment in order to derive testable hypotheses. The experiment was composed of two consecutive tasks, namely, a contest and a demand game. The contest is explained in the first subsection. It was used for allocating subjects' initial endowments. The protection hypothesis presupposes that initial endowments adequately reflect subjects' abilities. We did not induce abilities, but subjects took part in a multipleprize rank-order contest that involved a simple knowledge test. Assuming that subjects knew their own abilities to solve the knowledge test and had a guess about the distribution of abilities within the sample, which was made up of their fellow students, the contest ensured that more able subjects would expend more effort in order to win it. Effort was rewarded by assigning the first prize to the most able subject, the second prize to the second most able subject, and so on. The theoretical setup for the contest was taken from Moldovanu and Sela [22]. Sheremeta et al. [46] showed the rank-order contest to generate higher effort than lottery and proportional contests. $^{2}$

The demand game is explained in the second subsection. It was used for investigating the impact of different allocations of initial endowments and institutional setups on the acknowledgment of abilities and effort, respectively. Subjects first deliberated on sharing a surplus. As soon as the deliberation time had elapsed, they simultaneously and anonymously made their binding proposals for a distribution parameter. The proposal that achieved the quorum was played out and the surplus shares were added to the prize money won in the contest. If a group missed the quorum, the subjects received only their prizes. Such coordination and bargaining games with preplay communication (also known as cheap talk) have intensively been studied in the literature (for surveys see, e.g., [47-49]). The task determined the distribution parameter by vote and required a communication phase prior to finalizing the proposals such that group members could coordinate towards a distribution parameter capable of winning the necessary majority. In the context of our experiment, the results of Roth [50,51] are highly relevant, who showed that cheap talk focuses subjects' attention on a small number of fairness norms in unstructured bargaining experiments (see also [52]). More specifically, subjects identify initial bargaining positions that have some special reason for being credible and these serve as focal points.

In the third subjection, we derive testable hypotheses from the theoretical models. We first identify three potential focal points of the demand game, namely, the egalitarian solution, equal sharing, and proportional sharing. Then, each experimental setup is assigned its most likely sharing rule by theoretical consideration. We also analyze the possibility of disagreement. Finally, we argue by backward induction whether and how the sharing rule enacted in the demand game could impact subjects' willingness to expend effort in the contest.

3.1. The Contest. Following Moldovanu and Sela [22], we consider a contest with three prizes $\pi_{j}$, where $\pi_{1}>\pi_{2} \geq \pi_{3} \geq$ 0 . The total prize money $\Pi=\sum_{j=1}^{3} \pi_{j}$ has been exogenously fixed by the contest organizer. The set of contestants is given by $\mathscr{K}=\{A, B, C\}$. Individual effort is denoted by $x_{i}$, where we set $x_{A}>x_{B}>x_{C}$. The contest success function is perfectly discriminatory; that is, contestant $A$ is awarded the first prize $\pi_{1}$, contestant $B$ is awarded the second prize $\pi_{2}$, and contestant $C$ is awarded the third prize $\pi_{3}$. Making an effort involves a cost $c_{i} \gamma\left(x_{i}\right){ }^{3} \gamma$ is a strictly increasing function with $\gamma(0)=0 . c_{i}>0$ is an ability parameter. The lower is $c_{i}$, the higher is the ability of contestant $i$ and the lower is the cost of effort. 
Individual abilities are private information. They are independently drawn from the closed interval $[m, 1]$, where $m>0$, and have a continuous distribution function $F(c)$ which is common knowledge. To put it simply, we assume that ability follows a uniform distribution $F(c)=((1 /)$ $m)) c-m /(1-m)) I_{[m, 1]}(c)+I_{(1, \infty)}(c)$, where $I$ is an indicator function taking a value of one if $c$ is inside the stated interval and otherwise taking a value of zero. It can be shown (see Appendix $C$ in [22]) that in the Nash equilibrium individual effort is given by

$$
x(c)=\gamma^{-1}\left(\sum_{j=1}^{3} \pi_{j} \int_{c}^{1}-\frac{1}{a} F_{j}^{\prime}(a) d a\right),
$$

where

$$
\begin{aligned}
F_{j}^{\prime}(a)= & \frac{(3-1) !}{(j-1) !(3-j) !}(1-F(a))^{3-j-1} F(a)^{j-2} \\
& \cdot F^{\prime}(a)((1-3) F(a)+(j-1)) .
\end{aligned}
$$

In order to interpret (1), one has to realize that a subject's probability of wining prize $j, 1 \leq j \leq 3$, given her ability $a \in[m, 1]$, can be represented by an order statistic

$$
F_{j}(a)=\frac{(3-1) !}{(j-1) !(3-j) !}(1-F(a))^{3-j} F(a)^{j-1} .
$$

This equation takes into account that subject $j$ meets 2 competitors of whom $3-j$ are less able than $j$ and $j-1$ are more able. Equation (2) is the first derivative of (3) with respect to ability. Hence, the payoff-maximizing equilibrium effort stated in (1) is a function of the weighted sum of the three prizes, and the weights differ from subject to subject according to their abilities $c$. Shaked and Shanthikumar [53] have shown that, if $\gamma(c)$ is a strictly increasing function, effort is a monotonically decreasing function of the cost of ability $c$ and is zero at $c=1$. Hence, the most able subject will expend the highest effort and win the first price, the medium subject will win the second prize, and the least able subject will expend the lowest effort (but not necessarily zero effort) and win the third prize. Since there is a unique relation between ability, effort, and prize, in the following we will call the most able subject the $A$-player, the medium able subject the $B$ player, and the least able subject the $C$-player.

The bidding function (1) is too complex to be solved analytically for the "structural parameters" of the prize scheme that are of interest for us, namely, its mean, variance, and skewness. Nevertheless, clear predictions concerning subjects' effort reactions can be derived for each parameter change by numerical simulation. In Appendix A, we report the results of simulating a contest with $c=\{0.4,0.6,0.8\}$ and $m=0.2$, assuming linear cost functions. The predicted outcome for each prize scheme applied in the experiment is shown in Table 4. The columns list groups of three hypothetical subjects with their abilities, expected winning probabilities, expected returns, efforts, ranks, prizes, costs, and net payoffs (recall that subjects did not know the abilities of the other subjects, but supposedly only the distribution of ability). Table 5, also located in Appendix A, summarizes the information given in Table 4 by listing each prize scheme with its parametrization. ${ }^{4}$ Additionally it states the mean and the coefficient of variation of predicted effort. As can be seen from the table, predicted effort doubles if the prize money is doubled and if the coefficient of variation of the prize scheme is doubled, and it is almost halved when the prize scheme becomes right-skewed. Furthermore, within-group effort variation increases with a right-skewed prize scheme.

3.2. The Demand Game. The second task is a variation of the Nash demand game [54]. After awarding the prizes to the contestants, the contest organizer asks the contestants to make an arbitrary number of proposals $s=\left\{s_{A}, s_{B}, s_{C}\right\}$ for sharing a surplus $S=\Pi$; that is, total prize money is doubled. However, the surplus is made available only if one of the proposals is supported by a qualified majority of the group of contestants. If none prevails, the contestants receive only their prizes $\pi^{D}=\left\{\pi_{A}, \pi_{B}, \pi_{C}\right\}$ and exit the game (default option). If one of the proposals becomes accepted, it is made binding and the contestants receive their gross payoffs $\pi^{\alpha}=$ $\left\{\pi_{A}+s_{A}, \pi_{B}+s_{B}, \pi_{C}+s_{C}\right\}$. The following restriction applies to the set of feasible distributions of $S$ :

$$
s_{i}^{\alpha}=\alpha \pi_{i}+(1-\alpha)\left(\frac{2}{3} \Pi-\pi_{i}\right) \quad \forall i \in\{A, B, C\}, 0 \leq \alpha \leq 1 .
$$

It is straightforward to show that any feasible agreement $\alpha \epsilon$ $[0,1]$ would be weakly preferred by each contestant over the default option if $s_{i} \geq 0$ or $0 \leq \pi_{i} \leq(2 / 3) \Pi$. Hence, assuming that the latter condition holds, the default option can never be a Nash equilibrium. Conversely, any agreement is a Paretoefficient Nash equilibrium. We refer to $\alpha$ as the distribution parameter in the following. ${ }^{5}$

This unstructured bargaining protocol, in which subjects could first freely communicate and thereafter had to submit their binding proposals for $\alpha$ simultaneously and anonymously, is ideal for studying the distribution of the surplus and its interaction with the contest for two reasons (for a critical survey of bargaining theories and their experimental tests, see, e.g., [55]): First, existing experimental evidence clearly suggests that subjects coordinate on a small number of focal points or fairness norms in such settings. ${ }^{6}$ Distributions that could potentially serve as focal points in our experiment are addressed below. Second, the bargaining protocol allows for studying, apart from conflict of interest, the impact of different institutional settings in terms of voting rules on the frequency of disagreement as required for testing the Efficiency Hypothesis. ${ }^{7}$ Sequential bargaining protocols such as Rubinstein's [56] and, in its finite version, Baron and Ferejohn's [57] are inappropriate for studying our research questions because they exhibit unique subgame perfect Nash equilibria, and they assign proposer and responder roles to the players.

3.3. Focal Points and Hypotheses. The demand game outlined in the previous subsection has three potential focal points which correspond to different distribution principles or 


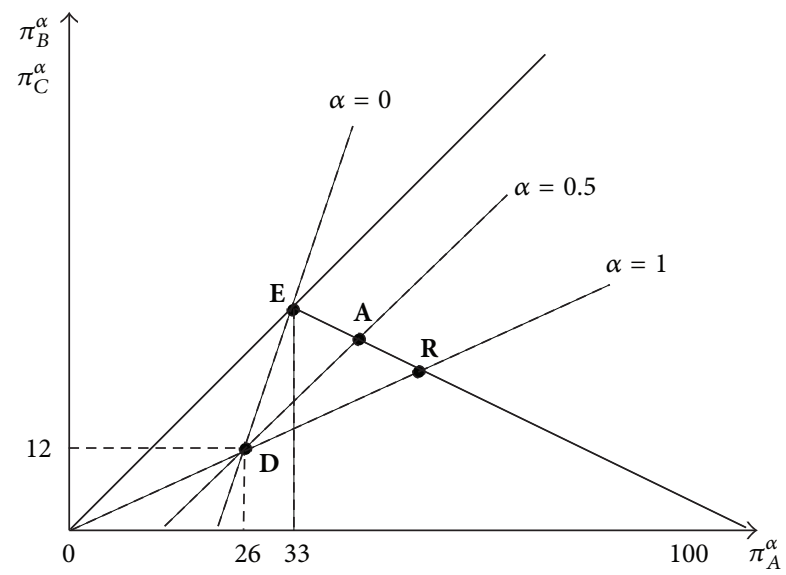

FIgURE 1: Sharing a surplus. The figure shows the gross payoffs $\pi_{i}^{\alpha}$ of players $i=A$ (horizontal axis) and $B$ and $C$ (vertical axis) for sharing a surplus of $S=\Pi=50$ with a right-skewed distribution of prizes $\pi=\{26,12,12\} . \overline{\mathbf{E R}}$ represents the bargaining set as well as the Pareto frontier. D marks the default option (no agreement). Three focal points $\mathbf{E}$ (egalitarian), A (equal sharing), and $\mathbf{R}$ (proportional sharing) are depicted together with their corresponding values of the distribution parameter $\alpha$.

fairness norms. Figure 1 gives a self-explaining example for a right-skewed distribution of prizes $\pi^{D}=(26,12,12)$. Total prize money and surplus are given by $\Pi=S=50$. The "budget line" $\overline{\mathbf{E R}}$ represent the bargaining set as well as the Pareto frontier. With regard to $\alpha$ we can distinguish three interesting special cases. First, for $\alpha=1$, we obtain a surplus distribution $s^{R}=\left\{s_{A}^{R}, s_{B}^{R}, s_{C}^{R}\right\}$, where $s_{i}^{R}=\pi_{i} \forall i \epsilon$ $\{A, B, C\}$, that is proportional to the prize money earned in the contest and, thus, has a strong positive correlation with effort. In comparison to the distribution of prizes $\pi^{D}=$ $\left\{\pi_{A}, \pi_{B}, \pi_{B}\right\}$ (point $\mathbf{D}$ ) the resulting gross payoff distribution $\pi^{R}=\left\{2 \pi_{A}, 2 \pi_{B}, 2 \pi_{C}\right\}$ (point $\mathbf{R}$ in the figure) preserves the degree of inequality measured by any relative (scale invariant) inequality measure. The equity standard underlying $\pi^{R}$ is well known as proportional sharing [58]. It targets the individual opportunity costs of the players [59].

Second, for $\alpha=0.5$, surplus is shared equally $s_{i}^{A}=$ $(1 / 3) \Pi$, proportional to the size of the surplus, and uncorrelated with effort. Compared with $\pi^{D}$ the distribution $\pi^{A}=$ $\left\{\pi_{A}+(1 / 3) \Pi, \pi_{B}+(1 / 3) \Pi, \pi_{C}+(1 / 3) \Pi\right\}$ does not change any absolute (translation invariant) inequality measure. The respective focal point is marked by point $\mathbf{A}$ in Figure 1. Moulin [58, page 162] argued that "any symmetric solution concept would divide equally the surplus." The equal sharing rule rewards cooperation rather than effort.

In the third case, $\alpha=0$ yields $s_{i}^{E}=(2 / 3) \Pi-\pi_{i}$, which is proportional to the gap between the equal share in total resources (prize money and surplus) and own prize. $s_{i}^{E}$ is negatively correlated with effort. An equal distribution of gross payoffs $\pi^{E}=\{(2 / 3) \Pi,(2 / 3) \Pi,(2 / 3) \Pi\}$ (point E) occurs (egalitarian solution). Here, the surplus is devoted to wiping out all inequality with regard to gross payoff by imposing a distribution principle which resembles Rawls'
[60] difference principle (though the demand game does not involve a veil of ignorance). However, if erroneously applied to gross income instead of net income, this principle penalizes effort by reversing the rank ordering produced by the contest.

As regards different setups of the demand game, we have the following expectations. The unanimity rule assigns every subject the same veto power regardless of her performance in the contest. Hence, subjects deal separately with the different tasks. In the default option of the demand game, the experimenter retains the surplus; that is, all subjects are treated alike in being given nothing. In line with the literature (see, e.g., [61]), we therefore conjecture the so-called symmetric solution, equal sharing $(\alpha=0.5)$, to be the only distribution standard compatible with the unanimity rule.

If the demand game is played with simple majority voting instead of the unanimity rule, we have to carefully distinguish between symmetric and right-skewed prize schemes. Let $\bar{\pi}=$ $(1 / 3) \Pi$ denote the equal share. The first derivative of (4) with respect to $\alpha$ is given by

$$
\frac{\partial s_{i}^{\alpha}}{\partial \alpha}=2\left(\pi_{i}-\bar{\pi}\right) .
$$

A payoff-maximizing subject would therefore vote for $\alpha=1$ if her prize money exceeds the equal share, she would vote for $\alpha=0$ if her prize money falls short of the equal share, and she would be indifferent if her prize money equals $\bar{\pi}$. In our experimental setup, right-skewed prize schemes consist of two prizes falling short of $\bar{\pi}$ and one prize exceeding it. Hence, the $B$ - and $C$-players are expected to agree on $\alpha=0$, giving rise to the egalitarian solution. In contrast to this, if a symmetric prize scheme applies, the $B$-player is indifferent because she cannot change her personal surplus share by voting on $\alpha$. The $B$-player's vote on the distribution parameter might be guided by social preferences. Inequity aversion would induce the $B$-player to agree with the $C$-player on an $\alpha<0.5$. On the other hand, if she acknowledges the higher ability of the $A$-player, she might agree with the $A$ player on an $\alpha>0.5$. The $B$-player might not be interested in $\alpha$ at all and just randomizes between the proposals of $A$ and $C$ in order to prevent the default option. Since, we have no a priori information about the distribution of $B$ 's preferences, we conjecture that any feasible agreement $\alpha \in[0,1]$ is equally likely. Hence, on average, we should observe that $\alpha=0.5$, the equal sharing distribution standard. These considerations lead to a testable version of the Protection Hypothesis.

(H1) Both unanimity rule and simple majority voting with a symmetric prize scheme result in a moderate level of redistribution ( $\alpha=0.5$, equal sharing). Simple majority voting with a right-skewed prize scheme leads to the lowest possible value of the distribution parameter; namely $\alpha=0$, the egalitarian solution.

Recall that any agreement $\alpha \in[0,1]$ is a Pareto-efficient Nash equilibrium. Nevertheless, default might occur if subjects decide to veto an agreement in order to prevent "unfair" outcomes. Then, they would sacrifice potential payoff in exchange for keeping the respective prize scheme intact. Obviously, subjects' veto power is highest if the decision 
mode is the unanimity rule. Furthermore, it is more difficult for three subjects to coordinate on a joint distribution standard than just for two as in the case, where $\alpha$ is determined by simple majority vote. These considerations lead to a testable version of the Efficiency Hypothesis.

(H2) Fixing the distribution standard by the unanimity rule involves more group disagreement in terms of default than simple majority voting and, therefore, is less efficient.

Finally, we have to address the issue whether subjects change their behavior in the contest when anticipating the results of the demand game. Large distribution parameters $1 \geq \alpha \geq 0.5$ definitely preserve the rank ordering determined by the contest in terms of net payoff. A risk neutral contestant would therefore plan her effort independent from the surplus sharing task. Small distribution parameters $0.5>\alpha \geq 0$ would punish effort and possibly reverse the rank ordering in terms of net payoff if $\alpha$ is sufficiently close to zero. In that case, the marginal return on effort becomes negative and effort is expected to diminish strongly. Hence, we can complement the Protection Hypothesis and the Efficiency Hypothesis by the following hypothesis.

(H3) Subjects on average expend less effort in contests with right-skewed prize schemes if the decision mode in the demand game is simple majority voting.

\section{Experimental Design}

The experiment was held in the experimental economics laboratory at the University of Bremen and the University of Oldenburg using z-Tree [62]. ${ }^{8}$ In total, 216 subjects participated in 12 sessions in the 90 -minute long experiments. Subjects were recruited using the recruitment system ORSEE [63]. About half of the subjects were female (45.6\%). 37\% of the participants were students of economics, $18 \%$ were students of social sciences, and the rest came from all other fields. Participants were on average in the sixth semester. At the outset, subjects were drawn from the subject pool and randomly assigned to a single session. No subject was allowed to take part more than once. We used anonymous random matching of the subjects assigned to a certain treatment into their respective groups. Hence, individual decisions should be independent from one another.

4.1. Treatment and Round Structure. The experiment involved four treatments that differed in

(i) the way subjects were allocated their initial endowments $\pi^{D}$ (contest, random);

(ii) the quorum required for fixing the distribution parameter $\alpha$ (majority, unanimity).

Our BASELINE treatment is contest $\times$ majority. Subjects first took part in a contest and then determined the distribution parameter for sharing the surplus by majority vote. ${ }^{9}$ In the VETo treatment unanimity was required, that is, every contestant was given the same veto power. We additionally conducted BASELINE and VETO without a contest in the first step. Here, initial endowments were randomly allocated to the subjects (CONTROL-B and ConTroL-V treatments). Each treatment involved eight rounds. Rounds differed as to the first three moments (mean, variance, and skewness) of the prize schemes. In each round, the prize scheme was presented to the subjects before the knowledge test started.

Given the structure of our experiment, treatment effects regarding the impact of the quorum and endowment allocation procedure are investigated at the between-subjects level. Treatment effects regarding the impact of the shape of the prize scheme are investigated at the within-subjects level. This procedure was chosen, on the one hand, in order not to confuse subjects with different voting and allocation mechanisms and, on the other hand, to study the impact of the variation of the moments of the prize scheme on the subjects' effort and distribution preferences. Apart from this argument, the number of subjects needed for the experiment shrunk by a factor of eight.

4.2. First Task: Knowledge Test. Subjects participated under time pressure in a contest. More specifically, they were presented ten questions differing in complexity which had been taken from an intelligence test. Questions were displayed in sequential order. Participants had a time restriction of 15 seconds per question. Going back and forth between questions was not possible. ${ }^{10}$ For each right (wrong) answer they obtained (lost) one point. Questions that remained unanswered after the time limit of 150 seconds yielded zero points. After having completed the test, subjects were randomly matched with two other subjects into groups of three. A subject's success in terms of points collected determined his or her $\operatorname{rank} i \in\{A, B, C\}$ in the group. A random number drawn from the unit interval was added to the number of collected points in order to avoid ties. Participants were informed about the procedure but were not informed whether they were actually affected.

In each round, each rank was endowed with a prize in tokens exchangeable for money at the end of the experiment. The respective amount was taken from the left of Table 1. Note that the number stated in the first column of the table is given for reference purposes only. The prize schemes were presented in randomized order to each group. ${ }^{11}$ After the end of the quiz, subjects learned their own ranks and the ranks of the other group members, and received their prize money according to the relevant prize scheme. ${ }^{12}$ They did not receive information about the absolute number of correctly solved tasks of any group member. The group assignment was renewed in every round (stranger design) in order to avoid supergame effects. ${ }^{13}$

An important feature of the set of prize schemes is that symmetric prize schemes render the B-player "neutral" because her final payoff is independent of $\alpha$. To see this, we plug $\pi_{B}=(1 / 3) \Pi$ into (4), which yields $s_{B}^{\alpha}=(1 / 3) \Pi$ for all $\alpha \in[0,1]$. Hence, it is only her "impartial" distribution attitude, which decides whether or not to agree, later on in the surplus-sharing task, with player $A$ or $C$ on a specific $\alpha$, and not self-interest. As opposed to this, right-skewed prize 
TABLE 1: Set of prize schemes.

\begin{tabular}{|c|c|c|c|c|c|c|}
\hline \multirow{3}{*}{ Number } & \multicolumn{3}{|c|}{ Rank } & \multirow{2}{*}{\multicolumn{3}{|c|}{$\begin{array}{l}\text { Parameters } \\
\text { Coefficient of }\end{array}$}} \\
\hline & $A$ & $B$ & $C$ & & & \\
\hline & 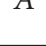 & $D$ & $C$ & Mean & Variation & Skewness \\
\hline 1 & 33 & 17 & 0 & 1 & $\mathrm{~h}$ & $s$ \\
\hline 2 & 67 & 33 & 0 & $\mathrm{~h}$ & $\mathrm{~h}$ & s \\
\hline 3 & 25 & 17 & 8 & 1 & 1 & s \\
\hline 4 & 50 & 33 & 17 & $\mathrm{~h}$ & 1 & s \\
\hline 5 & 36 & 7 & 7 & 1 & $\mathrm{~h}$ & $\mathrm{r}$ \\
\hline 6 & 72 & 14 & 14 & h & $\mathrm{h}$ & $\mathrm{r}$ \\
\hline 7 & 26 & 12 & 12 & 1 & 1 & $\mathrm{r}$ \\
\hline 8 & 52 & 24 & 24 & $\mathrm{~h}$ & 1 & $\mathrm{r}$ \\
\hline
\end{tabular}

Note. L: low, h: high, s: symmetric, and r: right-skewed.

schemes discriminate against the $B$-player by allocating the same prize money to her and $C$. Since $B$ tried harder than $C$, it is likely that her net payoff from the contest will fall below $C$ 's. Regardless of that, $B$ 's expected utility is higher than $C$ 's because she is more able and; therefore, she will expend more effort.

If subjects were assigned to the Control treatments their ranks $i \in\{A, B, C\}$ were determined by a random number generator instead of a contest. Everything else, in particular the parametrization of the rounds, stayed the same.

4.3. Second Task: Surplus Sharing. The second task involved a phase of preplay communication. Subjects were allowed to chat with their group mates about the distribution parameter to be fixed. For this purpose, we arranged a separate chat room for each group. A calculator for the gross payoff distribution was available during the whole task. The chat was available for three minutes at maximum. Afterwards, subjects were prompted to type in, simultaneously and anonymously, their preferred distribution parameter. The subjects were informed that if there was no agreement on a distribution parameter according to the necessary quorum, they would only receive their prize money. In BASELINE at least two group members had to type in exactly the same distribution parameter. In Vето all group members had to type in exactly the same distribution parameter in order to find an agreement. Note that the parametrization of the experiment secured that the distribution of the surplus for a given prize scheme was equivalent to redistributing half of total income (the sum of prize money and surplus). Each distribution standard $\alpha$ corresponded to a specific level of redistribution $\tau=1-\alpha{ }^{14}$ For example, the egalitarian distributional standard $\alpha=0$ corresponded to full redistribution $\tau=100$ percent. We favored the design of the experiment as a distributional problem over its presentation as a redistribution task because the chosen design highlights that in case of group default subjects are left alone with their individual outcomes from the contest and nobody can benefit from belonging to a group or society.

At the end of the experiment, after the eighth round had been played, one round was randomly selected for payoff.
The distribution parameter agreed upon by the group was applied for calculating the gross payoff. If subjects failed to reach an agreement in the surplus sharing task, they received only their prizes. Finally, tokens were converted at a rate of $4: 1$ into Euros. All payments were made in cash and in private. The minimum and the maximum possible payoffs were zero and 36 Euros, respectively. On average, subjects earned $€ 12.01(\approx$ US\$ 13.67) plus a show-up fee of $€ 5(\approx$ US\$ 5.69) for about 90 minutes of work.

\section{Results}

We present the results of our experiment in three steps. First, we investigate individual and group effort, then we compare the default rates between different treatments and prize schemes, and, finally, we report the results of testing the hypotheses regarding the outcome of the vote and relate them to effort choice. Furthermore, the outcome of the surplus sharing task after the contest is compared with a setup where the contest was replaced by a random generator.

5.1. Effort. Baseline and Veto were conducted each with 72 subjects, randomly forming $72 \times 8 / 3=192$ groups. We start off with the analysis of individual effort expended in the contest. The results of running separate fixed effects (FE) regressions for both treatments are presented in Table 2. We regressed individual effort on the parameters of the prize schemes, mean $(0=$ low, $1=$ high $)$, variance $(0=$ low, $1=$ high $)$, and skewness $(0=$ symmetric, 1 = right skewed). The expected signs of their coefficients are given in the last column of the table. The fit of these regressions is very low, which is not too surprising given the usual noise in experimental data and given the fact that we did not induce abilities. Varying mean and variance did not have a significant influence on individual effort. ${ }^{15}$ For skewness, we obtain a rather interesting pattern. In BASELINE, subjects behaved as expected by significantly reducing effort with right-skewed prize schemes. As opposed to this, in VETO subjects increased effort as compared to symmetric prize schemes. In the following, we will therefore concentrate on skewness, quorum, and their interaction.

Mean group effort across all treatments is 8.25 points. Figure 2 shows how group effort varied between treatments and prize schemes, each bar representing 96 group observations. As indicated by the FE regression, the mean difference between Veto and BASELINE is negative and insignificant $(-0.13$, SE: $0.51, P=0.399) .{ }^{16}$ Due to the opposing effect of skewness between treatments, the mean effort difference between symmetric and right-skewed prize schemes is insignificant too (0.27, SE: $0.51, P=0.300)$. In fact, mean group effort, like individual effort, decreases by 1.66 points (SE: 0.68 ) in BASELINE, which is highly significant $(P \leq 0.01)$, while it increases by 1.13 points (SE: 0.77$)$ in Veto, which is significant at the $10 \%$ level $(P=0.065)$.

We conclude that hypothesis $\mathbf{H 3}$ is clearly supported by our data both at the individual and at the group level. Subjects expended less effort in contests with right-skewed 
TABLE 2: Individual effort by treatment.

\begin{tabular}{lcccc}
\hline & Coefficient & SE & $P$ & $\begin{array}{c}\text { Expected } \\
\text { sign }\end{array}$ \\
\hline Mean & -0.281 & 0.231 & 0.228 & + \\
Variance & 0.038 & 0.209 & 0.855 & + \\
Skewness & -0.552 & 0.194 & 0.006 & - \\
Constant & 3.170 & 0.200 & 0.000 & \\
\hline$R^{2}$ & 0.0132 & & & \\
$F$ & 3.76 & & 0.015 & + \\
\hline Mean & -0.313 & 0.208 & 0.137 & + \\
Variance & -0.063 & 0.181 & 0.731 & + \\
Skewness & 0.375 & 0.222 & 0.095 & + \\
Constant & 2.729 & 0.180 & 0.000 & \\
\hline$R^{2}$ & 0.008 & & & \\
$F$ & 1.96 & & 0.128 & \\
\hline
\end{tabular}

Note. Fixed effects regression ( $n=72$ in both regressions). Endogenous variable: effort. SE: robust standard errors. Subject and period dummies. $P$ : significance level of a two-tailed $t$-test.

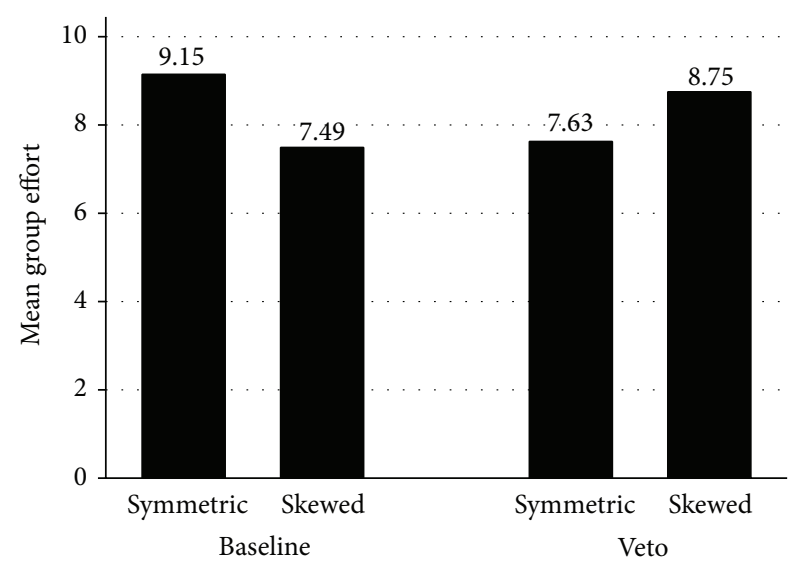

FIgURE 2: Mean effort. The figure shows mean group effort in points by treatment and prize scheme. $n=96$ for each bar.

prize schemes when the surplus sharing task involved the simple majority rule. Additionally, we observed the opposite effect for the Vето treatment, though the effect was less pronounced. In order to analyze our subjects' effort reactions to the anticipation of surplus distribution in the second part of the experiment more closely, we compiled the respective information on mean effort, separated by rank and treatment, in Table 6 in Appendix A. First focusing on simple majority voting, it becomes apparent that the decline of group effort was mainly due to the less able subjects $B$ and $C$ who expended significantly less effort when the contest involved a right-skewed prize scheme ( $B$-player: $P=0.004 ; C$ player: $P=0.043$ ), while the most able subject $A$ also showed a negative but insignificant reaction $(P=0.326)$. The unanimity rule induced all subjects to expend a bit more

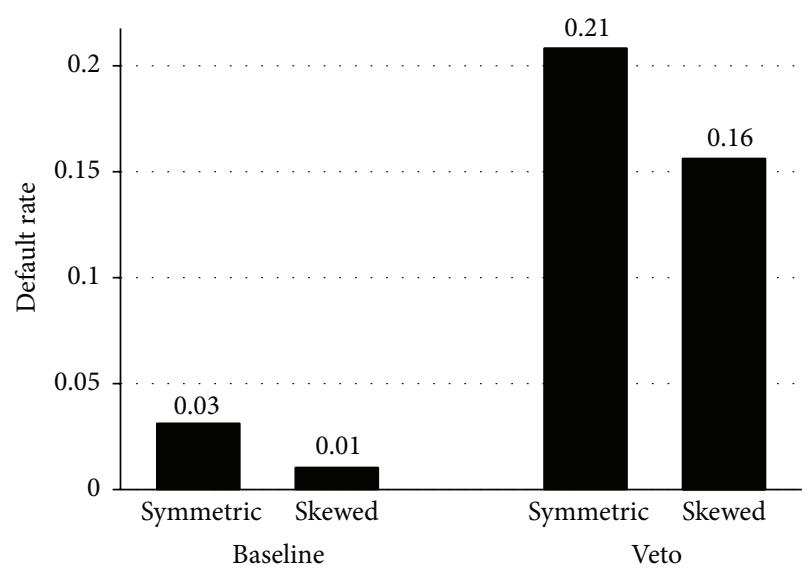

Figure 3: Default rates. The figure shows the default rate by treatment and prize scheme. $n=96$ for each bar.

effort when the contest involved a right-skewed prize scheme, but all differences are insignificant $(A$-player: $P=0.167 ; B$ player: $P=0.216$; $C$-player: $P=0.114)$. Hence, we refrain from speculating about the reasons for this effect.

5.2. Default. Before moving on to analyzing the distribution parameter, we have to filter out those groups that failed to come to an agreement. The overall default rate is $10.2 \%$. Figure 3 shows the default rates by treatment and prize scheme. As expected by the Efficiency Hypothesis, the unanimity requirement for $\alpha$ made default more likely in VETO than in BASELINE (mean difference: $16.1 \%$, SE: $3.0 \%, P \leq$ 0.01 ). At first sight, default rates also seem to be lower for right-skewed prize schemes, but the difference turned out to be insignificant at usual significance levels (3.6\%, SE: 3.1\%, $P=0.119$ ). Applying the test separately to each treatment does not change the result (BASELINE: 2.1\%, SE: 2.1\%, $P=$ 0.157; Veto: $5.2 \%$, SE: $5.6 \%, P=0.176$ ). We conclude that $\mathbf{H} 2$ is clearly supported by the data. Note that groups that failed at finding an agreement on $\alpha$ exhibited significantly lower group effort (0.769 points, SE: $0.276, P=0.003$ ). Default was not associated with higher within-group effort variation (mean difference: $-7.0 \%$, SE: $51.2 \%, P=0.554)$.

5.3. Distribution. After excluding groups that defaulted, 345 group observations remained, 188 (93/95) in BASELINE (symmetric/right-skewed) and 157 (76/81) in Veto. The mean of the distribution parameter across all groups is 0.366 ; that is, the average distribution attitude is a mixture between equal sharing (point $\mathbf{A}$ in Figure 1 ) and the difference principle (point E). However, the black bars in Figure 4 show $\alpha$ s of around 0.5 (equal sharing) for all situations except for BASELINE (majority) combined with right-skewed prize schemes. There, $\alpha$ is very close to zero, that is, the egalitarian distribution standard. Comparing means between treatments (Veto versus Baseline: 0.142, SE: $0.029, P \leq 0.01$ ) and between prize schemes (symmetric versus skewed: 0.236, SE: 0.027, $P \leq 0.01$ ) supports the Protection Hypothesis that 


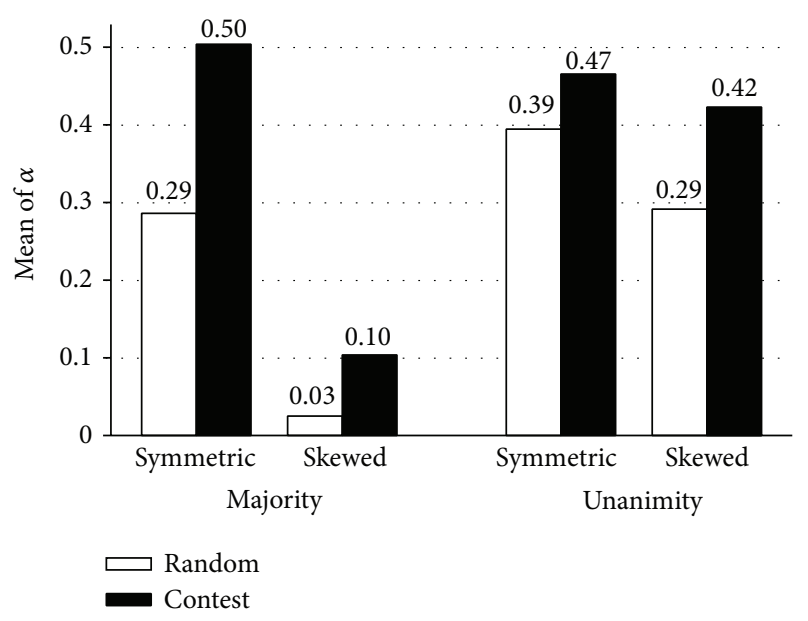

Figure 4: Distribution parameter. The figure shows the mean of the distribution parameter $\alpha$ by treatment and prize scheme. Black bars represent BASELINE and Veto (contest); $n=93,95,76$, and 81 group observations. White bars represent Control (random endowment); $n=48,48,47$, and 41 group observations.

unanimity requirement and symmetric prize schemes make strong (re)distribution less likely. The effect of skewness is more extreme in BASELINE but significant in both treatments (BASELINE: 0.400 , SE: $0.038, P \leq 0.01$; Veto: 0.043, SE: 0.029, $P=0.069)$.

We conclude that $\mathbf{H 1}$ is clearly supported by the data. Additionally, we take a glance at the final proposals for $\alpha$ submitted by the different players (the respective figures can be taken from the right panel of Table 6 in Appendix A). As implied by the Protection Hypothesis, it is mainly the $B$ player who is responsible for this result. When moving from symmetric to right-skewed prize schemes, her $\alpha$ drops from 0.51 - punctuating her neutrality - to $0.10(P \leq 0.01)$. It is also interesting to see that both the $A$-player and the $B$-player made concessions: when moving to a right-skewed prize scheme the $A$-player "offered" $\alpha=0.4$ instead of $\alpha=0.59$ $(P \leq 0.01)$; when moving to a symmetric prize scheme the $B$ player "offered" $\alpha=0.41$ instead of $\alpha=0.1(P \leq 0.01)$. In the VETO treatment, we observe significant differences between symmetric and right-skewed prize schemes with regard to the submitted $\alpha$ too ( $A$-player: $P=0.052$; $B$-player: $P=0.026$; $C$-player: $P=0.032$ ). Although all results are relatively close to equal sharing $(\alpha=0.4)$, subjects seem to have perceived the right skewed prize scheme less fair than the symmetric and, therefore, were willing to compensate the losers with a slightly larger share of the surplus. Finally, we would like to note that the dispersion of submitted distribution parameters was highest in BASELINE with right-skewed prize schemes, pointing to huge friction within the respective groups.

One could argue that the $\alpha$-values represented by the black bars do not relate to subjects' approval of individual effort or ability in the contest, but to their acceptance of the prize-schemes specified by the experimenter. In order to check for that objection, we set up the ConTrol treatment, where subjects were randomly endowed with the same set of "prizes" as in BASELINe and Veto. 72 subjects participated in Control. The white bars in Figure 4 represent the mean $\alpha$-values of the groups that did not default. There are two striking observations. First, the average height of the white bars is significantly lower than the black ones (0.247 versus 0.366 , mean difference: -0.119 , SE: $0.025, P \leq$ 0.01 ). This means that randomly endowing subjects gave rise to a more egalitarian distribution attitude. Groups strove towards wiping out inequality caused by chance rather than effort. Second, the white bars seem to replicate the black-bar pattern produced by the contest. The situation with majority vote and right-skewed initial endowment exhibits the lowest distribution parameter of only 0.03 .

Table 3 gives the difference of the group mean of $\alpha$ between contest and random endowment by quorum and prize scheme. All mean differences exhibit the expected sign and are significantly greater than zero at least at the 5 percent level. Figure 4 and Table 3 indicate that the difference between contest and random endowment is largest for situations involving symmetric endowments/prize schemes and majority vote. This conjecture is supported by the data, the difference of the mean differences of $\alpha$ between symmetric $\times$ majority and symmetric $\times$ unanimity is 0.147 (SE: 0.069 , $P=0.017$ ), right-skewed $\times$ majority is 0.087 (SE: 0.068 , $P=0.100$ ), and right-skewed $\times$ unanimity is 0.139 (SE: $0.064, P=0.015)$. All other pairwise difference tests are insignificant. In other words, if at all, individual effort in terms of success in a contest is acknowledged by a group majority only if the prize scheme is symmetric and the distribution of the surplus is determined by the majority vote. Despite the general acceptance of the outcome of the contests, groups on average agreed on a distribution parameter close to 0.5 , making equal sharing the dominant distribution motive. This setup was also associated with highest group effort (9.15, see Figure 2). The acceptance of the outcome of the contest shrunk dramatically with a right-skewed prize scheme. In this situation the majority agreed willingly on counteracting exante inequality by imposing the difference principle. Hence, default rates shrunk, but at the cost of lower effort. The unanimity requirement obviously shifted the focus away from effort towards cooperation in order to obtain the surplus. In that situation groups geared themselves to equal sharing combined with a small correction for ex-ante inequality. The respective $\alpha$-values fall below 0.5 and are almost independent from the shape of the prize scheme/endowment distribution.

\section{Conclusion}

In this paper, we experimentally test if both the existence of a middle class and institutional hurdles can protect the most able members of the society from the demand of the least able for excessive income distribution policies (Protection Hypothesis). We operationalized the institutional rule by the quorum needed for a group decision (majority versus unanimity) and the social structure by the existence of a middle class in contrast to a winner-take-all society. Moreover, we have argued that setting up institutional hurdles is inferior to relying on a middle class as institutional 
TABLE 3: Contest versus random endowment.

\begin{tabular}{lcc}
\hline Prize scheme & Majority & Quorum \\
\hline \multirow{3}{*}{ Symmetric } & 0.218 & Unanimity \\
& $(0.057)$ & 0.071 \\
& $P \leq 0.01$ & $(0.035)$ \\
Right-skewed & 0.079 & $P=0.022$ \\
& $(0.029)$ & 0.131 \\
& $P \leq 0.01$ & $(0.031)$ \\
\hline
\end{tabular}

Note. First row: mean difference of $\alpha$ between contest and random. Second row: standard errors. Third row: significance level of a one-tailed $t$-test.

hurdles involve efficiency losses due to bargaining impasses (Efficiency Hypothesis).

The experiment directly tests our main hypotheses. We find that the Protection Hypothesis is clearly supported by our data. The existence of a neutral middle class is as effective as institutional hurdles to protect the rich from being expropriated. Hereby, the middle class balances the interests of the poor and the rich. The middle class does not have an interest in excesses from one side because redistribution shifts money from the rich to the poor. We argue that the middle class can be interpreted as an uninvolved spectator who has no interest to favor one group over another. The Efficiency Hypothesis is also supported. Institutional hurdles come at the cost of significantly less efficiency in terms of higher default rates. Hereby, a higher default rate means that the payoff for both the rich and the poor is lower. Even, at the individual level, we could observe that subjects expend more effort if the prize scheme involved a moderating middle player. The corroboration of both hypotheses allows us to draw the conclusion that the middle class is the efficient protection of the rich.

We contribute to the literature about why the rich do not get expropriated. Leaving aside the branch of the literature which summarizes the reasons of why the poor do not expropriate the rich (e.g., beliefs, identity, and social preferences of the poor), we study a constellation in which the rich can actively protect themselves from being expropriated. Although any extrapolation of our laboratory results has to be done carefully, we note that our finding that collective decisions have been less equalizing and more efficient under the majority rule with a neutral middle player than in groups with a right-skewed prize structure resonates well with the empirical data, supporting the warnings about the impact of rising inequality on societal stability and economic growth in contemporary societies. Coming back to the empirical findings in the introduction: not only the middle class itself but also the rich should have an interest in bracing against the erosion of the middle class.

\section{Appendices}

\section{A. Further Tables}

See Tables 4, 5, and 6 .

\section{B. Instructions}

B.1. Welcome to the Experiment and Thank You for Participating! Please do not talk to other participants during the entire experiment! During the experiment, you have to make several decisions. Your individual payoff depends on your own decision and the decisions of your group members due to the following rules. You will be paid individually, privately, and in cash after the experiment. During the experiment, we will talk about Tokens as the experimental currency. After the experiment, Tokens will be transferred into Euros with the following exchange rate:

$$
10 \text { Tokens }=2.50 \text { Euros. }
$$

Please take your time reading the instructions and making your decisions. You are not able to influence the duration of the experiment by rushing through your decisions because you always have to wait until the remaining participants have reached their decisions. The experiment is completely anonymous. At no time during the experiment or afterwards will the other participants know which role you were assigned to and how much you have earned.

If you have any questions please raise your hand. One of the experimenters will come to you and answer your questions privately. Following this rule is very important. Otherwise the results of this experiment will be worthless for scientific purposes. You will receive a show-up fee of 5 Euros for your participation. Depending on your decisions and the decisions of the other participants you can additionally earn up to 144 Tokens (36 Euros). The expected duration of the experiment is 90 minutes. The exact course of the experiment will be described in the following.

B.2. Detailed Information. The experiment consists of 8 rounds which all follow the same course. In each round participants will be randomly and repeatedly assigned to groups of three members. Your payoff will be determined only by your own decisions and decisions of the other group members. Decisions of the other groups do not affect your payment. No participant receives information about other subjects' final choices, although group members have the possibility to communicate via chat to find an agreement. The final decisions are anonymous within each group.

After the group assignment, a knowledge test follows (in the control treatments, ranks were assigned by a random generator instead of the knowledge test). The more questions you answer correctly in the knowledge test, the higher your potential payoff at the end of the experiment will be. The knowledge test consists of various tasks. For each correctly solved task you receive one point; each question you answered incorrectly, a point is subtracted, and for not answering questions you do not get any points. Based on the collected points you will be assigned a rank within the group. The player with the highest score in the knowledge test gets the highest rank (rank 1) and also the highest token endowment. The player with the lowest number of collected points will be assigned the lowest rank (rank 3) and also the lowest token endowment. 
TABLE 4: Predictions for the contest.

\begin{tabular}{|c|c|c|c|c|c|c|c|c|c|c|c|}
\hline \multirow{2}{*}{$\begin{array}{l}\text { Prize } \\
\text { scheme }\end{array}$} & \multirow{2}{*}{$\begin{array}{c}\text { Player } \\
i\end{array}$} & \multirow{2}{*}{$\begin{array}{c}\text { Ability } \\
c_{i}\end{array}$} & \multicolumn{3}{|c|}{$\begin{array}{l}\text { Expected winning } \\
\text { probabilities (\%) }\end{array}$} & \multirow{2}{*}{$\begin{array}{c}\text { Expected } \\
\text { return } \\
E\left(\pi_{i}\right)\end{array}$} & \multirow{2}{*}{$\begin{array}{c}\text { Effort } \\
x_{i}\end{array}$} & \multirow{2}{*}{$\begin{array}{c}\text { Rank } \\
j\end{array}$} & \multirow{2}{*}{$\begin{array}{c}\text { Prize } \\
\pi_{j}\end{array}$} & \multirow[t]{2}{*}{ Cost } & \multirow[t]{2}{*}{$\begin{array}{l}\text { Net } \\
\text { payoff }\end{array}$} \\
\hline & & & 1 st & 2nd & $3 \mathrm{rd}$ & & & & & & \\
\hline \multirow{3}{*}{1} & 1 & 0.4 & 56.2 & 37.5 & 6.2 & 10 & 38 & $\mathrm{~A}$ & 33 & 15 & 18 \\
\hline & 2 & 0.6 & 25.0 & 50.0 & 25.0 & 4 & 21 & B & 17 & 13 & 4 \\
\hline & 3 & 0.8 & 6.2 & 37.5 & 56.2 & 1 & 9 & $\mathrm{C}$ & 0 & 8 & -8 \\
\hline \multirow{3}{*}{2} & 1 & 0.4 & 56.2 & 37.5 & 6.2 & 19 & 77 & A & 67 & 31 & 36 \\
\hline & 2 & 0.6 & 25.0 & 50.0 & 25.0 & 8 & 42 & B & 33 & 25 & 8 \\
\hline & 3 & 0.8 & 6.2 & 37.5 & 56.2 & 2 & 18 & $\mathrm{C}$ & 0 & 15 & -15 \\
\hline \multirow{3}{*}{3} & 1 & 0.4 & 56.2 & 37.5 & 6.2 & 13 & 20 & $\mathrm{~A}$ & 25 & 8 & 17 \\
\hline & 2 & 0.6 & 25.0 & 50.0 & 25.0 & 10 & 11 & B & 17 & 7 & 10 \\
\hline & 3 & 0.8 & 6.2 & 37.5 & 56.2 & 8 & 5 & $\mathrm{C}$ & 8 & 4 & 4 \\
\hline \multirow{3}{*}{4} & 1 & 0.4 & 56.2 & 37.5 & 6.2 & 27 & 38 & A & 50 & 15 & 35 \\
\hline & 2 & 0.6 & 25.0 & 50.0 & 25.0 & 21 & 21 & B & 33 & 12 & 21 \\
\hline & 3 & 0.8 & 6.2 & 37.5 & 56.2 & 18 & 9 & $\mathrm{C}$ & 17 & 7 & 10 \\
\hline \multirow{3}{*}{5} & 1 & 0.4 & 56.2 & 37.5 & 6.2 & 12 & 29 & $\mathrm{~A}$ & 36 & 11 & 25 \\
\hline & 2 & 0.6 & 25.0 & 50.0 & 25.0 & 8 & 10 & B & 7 & 6 & 1 \\
\hline & 3 & 0.8 & 6.2 & 37.5 & 56.2 & 7 & 2 & $\mathrm{C}$ & 7 & 2 & 5 \\
\hline \multirow{3}{*}{6} & 1 & 0.4 & 56.2 & 37.5 & 6.2 & 24 & 57 & A & 72 & 23 & 49 \\
\hline & 2 & 0.6 & 25.0 & 50.0 & 25.0 & 16 & 20 & $\mathrm{~B}$ & 14 & 12 & 2 \\
\hline & 3 & 0.8 & 6.2 & 37.5 & 56.2 & 14 & 4 & $\mathrm{C}$ & 14 & 3 & 11 \\
\hline \multirow{3}{*}{7} & 1 & 0.4 & 56.2 & 37.5 & 6.2 & 14 & 14 & A & 26 & 6 & 20 \\
\hline & 2 & 0.6 & 25.0 & 50.0 & 25.0 & 13 & 5 & B & 12 & 3 & 9 \\
\hline & 3 & 0.8 & 6.2 & 37.5 & 56.2 & 12 & 1 & $\mathrm{C}$ & 12 & 1 & 11 \\
\hline \multirow{3}{*}{8} & 1 & 0.4 & 56.2 & 37.5 & 6.2 & 29 & 28 & $\mathrm{~A}$ & 52 & 11 & 41 \\
\hline & 2 & 0.6 & 25.0 & 50.0 & 25.0 & 25 & 10 & B & 24 & 6 & 18 \\
\hline & 3 & 0.8 & 6.2 & 37.5 & 56.2 & 24 & 2 & $\mathrm{C}$ & 24 & 2 & 22 \\
\hline
\end{tabular}

Note. Predictions for a 3-player contest with linear cost functions and maximum ability, $m=0.2$.

TABle 5: Predicted effort by prize scheme.

\begin{tabular}{lccccc}
\hline $\begin{array}{l}\text { Prize } \\
\text { scheme }\end{array}$ & Mean & $\begin{array}{l}\text { Coefficient } \\
\text { of variation }\end{array}$ & Skewness & \multicolumn{2}{c}{$\begin{array}{c}\text { Effort } \\
\text { Mean }\end{array}$} \\
\hline 1 & 0 & 1 & 0 & 22.9 & .6 \\
2 & 1 & 1 & 0 & 45.9 & .6 \\
3 & 0 & 0 & 0 & 11.9 & .6 \\
4 & 1 & 0 & 0 & 22.5 & .6 \\
5 & 0 & 1 & 1 & 13.6 & 1.0 \\
6 & 1 & 1 & 1 & 27.2 & 1.0 \\
7 & 0 & 0 & 1 & 6.6 & 1.0 \\
8 & 1 & 0 & 1 & 13.1 & 1.0 \\
\hline
\end{tabular}

Note. $0=$ low/symmetric, $1=$ high/right-skewed. Effort predictions according to Table 4.

The knowledge test is designed with a time restriction of 150 seconds for 10 screens with different tasks. The tasks come from different fields. Each question has only one correct answer. You have 15 seconds per question. Please pay attention to the time restriction in the upper right corner
TABLE 6: Effort and distribution proposal by treatment.

\begin{tabular}{lcccccc}
\hline \multirow{7}{*}{ Prize scheme } & \multicolumn{7}{c}{ Subject's rank } \\
& $A$ & $B$ & $C$ & $A$ & $B$ & $C$ \\
\hline \multirow{5}{*}{ Symmetric } & 4.39 & 3.14 & 1.63 & 0.59 & 0.51 & 0.41 \\
& $(0.22)$ & $(0.20)$ & $(0.32)$ & $(0.03)$ & $(0.03)$ & $(0.03)$ \\
Right-skewed & 4.26 & 2.38 & 0.85 & 0.40 & 0.10 & 0.10 \\
& $(0.17)$ & $(0.20)$ & $(0.30)$ & $(0.04)$ & $(0.02)$ & $(0.02)$ \\
\hline \multirow{7}{*}{ Symmetric majority voting } & 3.92 & 2.55 & 1.16 & 0.48 & 0.49 & 0.47 \\
& $(0.21)$ & $(0.21)$ & $(0.31)$ & $(0.02)$ & $(0.02)$ & $(0.02)$ \\
Right-skewed & 4.24 & 2.80 & 1.72 & 0.43 & 0.41 & 0.43 \\
& $(0.26)$ & $(0.22)$ & $(0.35)$ & $(0.02)$ & $(0.03)$ & $(0.02)$ \\
\hline
\end{tabular}

Note. The figures give the subjects' mean scores in the intelligence test (per round) and the mean of the distribution parameter $\alpha$ typed in after the chat phase. Standard errors are in parentheses.

of the screen. By clicking on the OK button you can get to the next screen. After a total of 150 seconds, the knowledge 
test stops and the collected points are summed up. The ranks and the associated endowments will be provided after the knowledge test, explanations, and further instructions.

B.3. After the Knowledge Test. You have collected points in the knowledge test. According to the collected points of all group members each group member will be assigned a rank and a certain endowment of tokens. The ranking reflects directly the performance in the knowledge test of the group's members (in the control treatment the ranks and endowment were assigned randomly). The token endowment varies from round to round. A total of 8 rounds will be played. The sequential arrangement of token distributions will be chosen randomly.

B.4. Decision about Payoff Distribution by Choosing a Distribution Parameter. In the experiment, you will see on the next screen your own rank and token endowment and the ranks and token endowments of your group members. In the following you and your group members have to determine the distribution parameter. You should set a distribution parameter which distributes tokens between the group members in such a way that your preferences are met. The payoff of the group member $X=1,2,3$ at the end of the experiment is then calculated as follows:

$$
\begin{aligned}
\text { Payoff } X= & \text { Tokens } X \cdot(1-t) \\
& +\frac{(\text { Tokens } 1+\text { Tokens } 2+\text { Tokens } 3) \cdot t}{3} .
\end{aligned}
$$

Distribution only takes place when at least 2 (3, under unanimity rule) group members choose the same distribution parameter. The chosen distribution parameter determines the final distribution within the group in that period. Sample calculation: player 1 has 3 tokens, player 2 has 5 tokens, and player 3 has 10 tokens. Given that order, players chose the following distribution parameters: $81 \%$ (50\%, under unanimity rule), $50 \%$, and $50 \%$. The distribution parameter, which determines the level of redistribution, is thus $50 \%$. The payoff for player 1 is

$$
\text { Payoff } 1=3 \cdot(1-0.5)+\frac{(3+5+10) \cdot 0.5}{3}=1.5+3=4.5 \text {. }
$$

The computer calculates the payoffs under the assumption that the distribution parameter you make is the relevant distribution parameter which will be implemented.

If not at least 2 (3, under unanimity rule) players from the group typed in the same distribution parameter, no distribution takes place and players receive only their token endowment determined by their rank in the knowledge test. In the example above, this would mean that if the players chose distribution parameters of $96 \%, 51 \%$, and $7 \%$ and therefore no agreement is reached, player 1 receives only 1.5 tokens. The same would apply to the endowments of the remaining players.
B.5. Possibility to Communicate (Open or Restricted). You have the possibility to chat with the other group members in a joint chat room. You can chat freely (restricted in the way that you can only type in numbers between 0 and 100, under restricted communication rule) and discuss which distribution parameter is to be implemented, but you are not allowed to reveal your identity.

Chat time is restricted to 3 minutes. If not at least 2 (3, under unanimity rule) players have entered the same distribution parameters in time and have confirmed their chosen distribution parameters by clicking the OK button, then no distribution will take place.

The calculator is available to you for trying out different distribution parameters. To get an impression about the chat structure, the endowments and the tokens, and the calculator, a sample screen is given below. In the upper part of the screen you see the group chat room. The rank number of each player is displayed directly above and within the chat window. In the lower part of the screen the ranks and tokens of all group members before and after distribution are displayed. In the right field, you can enter as often as you wish different distribution parameters to calculate the final token distribution. In this example, the final distribution is calculated as follows: the distribution parameter is $45 \%$. Hence, $45 \%$ of $6=2.7,45 \%$ of $10=4.5$, and $45 \%$ of $4=1.8$ are subtracted from the players' accounts, resulting in a sum of 9 Tokens. Dividing the sum by 3 gives 3 Tokens to be distributed to each group member. The final distribution then is given by $6-2.7+3=6.3,10-4.5+3=8.5$, and $4-1.8+3=5.2$ Tokens. For example, using the equation given above, the payoff of player 3 would be given by

$$
\text { Payoff }=4 \cdot(1-0.45)+\frac{(4+6+10) \cdot 0.45}{3}=2.2+3=5.2 .
$$

Pressing the OK button confirms and completes the decision.

B.6. Calculation of the Payoffs. One of the 8 rounds is randomly selected for payoff. Each round could therefore be payoff relevant. Individual payoffs will be calculated according to the chosen distribution parameter and the rules stated above. The experiment will begin shortly. If you have questions, please raise your hand and wait quietly until an experimenter comes to you. Speaking with other participants is strictly prohibited throughout the experiment. Thank you and have fun in the experiment.

\section{Conflict of Interests}

The authors declare that there is no conflict of interests regarding the publication of this paper.

\section{Acknowledgments}

The authors thank two anonymous referees and the editors, in particular Klarita Gërxhani, for their comments and support. This research was partly financed by the NOWETAS Foundation under the project title "Decision making among 
collectives and the individual: the interdisciplinary analysis of perceptions of justice in collective decision processes and their feedback to the individual level" and by the German Research Foundation (DFG), research group FOR 2104: "Needs-based justice and distribution procedures" (Traub: TR 458/6-1). They would like to thank Nicola Maaser and the participants of several research seminars and the workshop "Positive and Normative Aspects of Distributive Justice: An Interdisciplinary Perspective" held at the University of Bremen, in particular, for their most helpful comments and suggestions.

\section{Endnotes}

1. A similar effect of voting was reported by Frohlich and Oppenheimer [64].

2. For more general information on contest theory, we refer to the surveys by Corchón [65] and Konrad 42]. Experimental research on contests was recently surveyed by Dechenaux et al. [66]. Multiple-prize contests have intensively been investigated with respect to the optimality of the prize scheme in terms of maximum effort generation (see, e.g., [67]).

3. In general, the cost of effort include all monetary and nonmonetary costs such as cognitive effort and time. In our experiment, the only costs of solving questions in the intelligence test were cognitive. Time consumption was equal for all subjects and covered by a show-up fee.

4. The numbers listed in both tables are only point estimates for a single distribution of ability. One could extend the simulation by randomly drawing $c$ from $F(c)$ a sufficiently large number of times in order to obtain confidence intervals for mean effort. However, since the stylized facts would stay unchanged, we save the effort.

5. Note that the restriction $s_{i} \geq 0$ implies that the subjects' rank ordering according to their prizes cannot be reversed by the surplus sharing task. This parallels the condition stated by Meltzer and Richard [23] that the median voter's tax rate is utility maximizing only if it does not exceed one and therefore preserves the rank ordering between productive and less productive individuals.

6. A loosely related study by Selten and Ockenfels [68] found a relative majority of subjects to comply with a fairness norm they called "fixed total sacrifice." Subjects were willing to donate a fixed amount of money to the losers of a solidarity game irrespective of the number of losers. In a game studied by Okada and Riedl [69] proposers could form different coalitions of up to three players and then distribute the coalition surplus among the coalition members. In most cases, the proposer chose an inefficient two-person coalition and the responder reciprocated the choice of the proposer by not rejecting the unfair proposal that excluded a third of the population from payoff.
7. Goeree and Yariv [70] found that deliberation blurs differences between institutions (e.g., in terms of voting rules) and uniformly improves efficiency of group outcomes. We borrow from the work of these authors by considering two different voting rules under which the surplus-sharing game is conducted, namely, simple majority voting and unanimity rule. In so far, our study is also related to the literature on deliberation in collective decision making (see [70-72]). For an overview of the experimental literature on deliberation, see Karpowitz and Mendelberg [73].

8. For a transcript of the instructions see Appendix B.

9. We have also varied the chat possibilities in such a way that in half of the sessions participants could exchange full text messages and in the remaining sessions participants could only exchange numbers. Due to the fact that we do not find any differences between these sessions, we decided to pool these sessions.

10. The questions compassed mathematical, linguistical, and combinatorial tasks.

11. Note that the stranger matching protocol requires keeping the randomization of the ordering of the prize schemes constant in each session. Since we conducted four sessions per treatment, we used four predefined randomizations that stayed the same for all treatments in order to control for eventual path-dependencies.

12. Prize schemes 5 and 6 slightly violate the nonnegativity constraint for $s_{i}^{\alpha}$ for large $\alpha$-values. This is due to the construction of the set of prize schemes, where half of the eight different prize schemes exhibit the same mean, variation coefficient, and skewness, respectively.

13. Note that the theoretical model of the contest outlined in Section 3 has to assume that subjects know their own abilities and the distribution of abilities in order to derive the result that those who are more able also expend more effort. We did not collect subjects' expectations about their abilities and winning probabilities in the experiment, but it could be interesting to check whether their beliefs were correct and to compare their goodness of fit with the outcome of the contest.

14. As can be taken from the instructions, we let subjects enter $\tau$ instead of $\alpha$, which turned out to be more intelligible in pilot experiments.

15. We also expected right-skewed prize schemes to increase within-group effort variation among contestants. Analyzing effort variation again speaks a slightly different language. Indeed, it seems to increase in BASELINE. However, the mean difference turns out to be insignificant (0.34, SE: $0.53, P=0.259)$. In Veto, the mean difference has the wrong sign, but it is significant $(0.65$, SE: 0.28 , $P=0.012$ ).

16. Significance level of a one-tailed $t$-test. Tests regarding directional hypothesis are one-tailed unless otherwise specified. SE: standard error. 


\section{References}

[1] T. Piketty, Capital in the Twenty-First Century, Belknap Press, Cambridge, Mass, USA, 2014.

[2] OECD, Growing Unequal? Income Distribution and Poverty in OECD Countries, OECD, Paris, France, 2008.

[3] S. K. Singh and G. S. Maddala, "A function for size distribution of incomes," Econometrica, vol. 44, no. 5, pp. 963-970, 1976.

[4] C. Seidl, K. Pogorelskiy, and S. Traub, Tax Progression in OECD Countries. An Integrative Analysis of Tax Schedules and Income Distributions, Springer, Berlin, Germany, 2013.

[5] R. H. Frank and P. Cook, The Winner-Take-All Society, Free Press, New York, NY, USA, 1995.

[6] R. H. Frank, How Rising Inequality Harms the Middle Class, University of California Press, Berkely, Calif, USA, 2007.

[7] J. S. Hacker and P. Pierson, Winner-Take-All Politics. How Washington Made the Rich Richer-and Turned Its Back on the Middle Class, Simon \& Schuster, New York, NY, USA, 2010.

[8] S. Rosen, "The economics of superstars," The American Economic Review, vol. 71, no. 5, pp. 845-858, 1981.

[9] T. A. DiPrete and G. M. Eirich, "Cumulative advantage as a mechanism for inequality: a review of theoretical and empirical developments," Annual Review of Sociology, vol. 32, pp. 271-297, 2006.

[10] E. Franck and S. Nüesch, "Talent and/or popularity: what does it take to be a superstar?" Economic Inquiry, vol. 50, no. 1, pp. 202-216, 2012.

[11] J. E. Stiglitz, The Price of Inequality: How Today's Divided Society Endangers Our Future, W. W. Norton \& Company, New York, NY, USA, 2012.

[12] F. Fukuyama, The End of History and the Last Man, Free Press, New York, NY, USA, 1992.

[13] A. Alesina and G.-M. Angeletos, "Fairness and redistribution," American Economic Review, vol. 95, no. 4, pp. 960-980, 2005.

[14] J. M. Buchanan and G. Tullock, The Calculus of Consent. Logical Foundations of Constitutional Democracy, University of Michigan Press, Ann Arbor, Mich, USA, 1962.

[15] L. Miller and C. Vanberg, "Decision costs in legislative bargaining: an experimental analysis," Public Choice, vol. 155, no. 3-4, pp. 373-394, 2013.

[16] F. W. Scharpf, "A game-theoretical interpretation of inflation and unemployment in Western Europe," Journal of Public Policy, vol. 7, no. 3, pp. 227-257, 1987.

[17] W. Easterly, "The middle class consensus and economic development," Journal of Economic Growth, vol. 6, no. 4, pp. 317-335, 2001.

[18] E. Glaeser, J. Scheinkman, and A. Shleifer, "The injustice of inequality," Journal of Monetary Economics, vol. 50, no. 1, pp. 199-222, 2003.

[19] W. Arts and J. Gelissen, "Welfare states, solidarity and justice principles: does the type really matter?" Acta Sociologica, vol. 44, no. 4, pp. 283-299, 2001.

[20] L. d'Anjou, A. Steijn, and D. van Aarsen, "Social position, ideology, and distributive justice," Social Justice Research, vol. 8, no. 4, pp. 351-384, 1995.

[21] M. M. Jæger, "What makes people support public responsibility for welfare provision: self-interest or political ideology? A longitudinal approach," Acta Sociologica, vol. 49, no. 3, pp. 321338, 2006.
[22] B. Moldovanu and A. Sela, "The optimal allocation of prizes in contests," American Economic Review, vol. 91, no. 3, pp. 542-558, 2001.

[23] A. H. Meltzer and S. F. Richard, "A rational theory of the size of government," Journal of Political Economy, vol. 89, no. 5, pp. 914-927, 1981.

[24] R. Perotti, "Growth, income distribution, and democracy: what the data say," Journal of Economic Growth, vol. 1, no. 2, pp. 149$187,1996$.

[25] A. Alesina and R. Perotti, "Income distribution, political instability, and investment," European Economic Review, vol. 40, no. 6, pp. 1203-1228, 1996.

[26] R. Benabou and E. A. Ok, "Social mobility and the demand for redistribution: the POUM hypothesis," Quarterly Journal of Economics, vol. 116, no. 2, pp. 447-487, 2001.

[27] J. E. Roemer, "Why the poor do not expropriate the rich: an old argument in new garb," Journal of Public Economics, vol. 70, no. 3, pp. 399-424, 1998.

[28] J. E. Roemer and W. Lee, "Racism and redistribution in the United States: a solution to the problem of American exceptionalism," Journal of Public Economics, vol. 90, no. 6-7, pp. 10271052, 2006.

[29] C. Fong, "Social preferences, self-interest, and the demand for redistribution," Journal of Public Economics, vol. 82, no. 2, pp. 225-246, 2001.

[30] N. Frohlich and J. A. Oppenheimer, Choosing Justice: An Experimental Approach to Ethical Theory, University of California Press, Ewing, NJ, USA, 1993.

[31] D. Miller, Principles of Social Justice, Harvard University Press, Cambridge, Mass, USA, 1999.

[32] J. Konow, "Which is the fairest one of all? A positive analysis of justice theories," Journal of Economic Literature, vol. 41, no. 4, pp. 1188-1239, 2003.

[33] S. Traub, C. Seidl, U. Schmidt, and M. V. Levati, "Friedman, Harsanyi, Rawls, Boulding-or somebody else? An experimental investigation of distributive justice," Social Choice and Welfare, vol. 24, no. 2, pp. 283-309, 2005.

[34] A. Sen, The Idea of Justice, Belknap Press, Cambridge, Mass, USA, 2009.

[35] W. Gaertner and E. Schokkaert, Empirical Social Choice. Questionnaire-Experimental Studies on Distributive Justice, Cambridge University Press, Cambridge, UK, 2012.

[36] E. F. Klor and M. Shayo, "Social identity and preferences over redistribution," Journal of Public Economics, vol. 94, no. 3-4, pp. 269-278, 2010

[37] J.-R. Tyran and R. Sausgruber, "A little fairness may induce a lot of redistribution in democracy," European Economic Review, vol. 50, no. 2, pp. 469-485, 2006.

[38] E. Fehr and K. M. Schmidt, "A theory of fairness, competition, and cooperation," Quarterly Journal of Economics, vol. 114, no. 3, pp. 817-868, 1999.

[39] W. Höchtl, R. Sausgruber, and J.-R. Tyran, "Inequality aversion and voting on redistribution," European Economic Review, vol. 56, no. 7, pp. 1406-1421, 2012.

[40] G. E. Bolton and A. Ockenfels, "Inequality aversion, efficiency, and maximin preferences in simple distribution experiments: comment," American Economic Review, vol. 96, no. 5, pp. 19061911, 2006.

[41] K. D. Messer, G. L. Poe, D. Rondeau, W. D. Schulze, and C. Vossler, "Exploring voting anomalies using a demand revealing 
random price voting mechanism," Journal of Public Economics, vol. 94, pp. 308-317, 2010.

[42] F. Paetzel, R. Sausgruber, and S. Traub, "Social preferences and voting on reform: an experimental study," European Economic Review, vol. 70, pp. 36-55, 2014.

[43] L. Balafoutas, M. G. Kocher, L. Putterman, and M. Sutter, "Equality, equity and incentives: an experiment," European Economic Review, vol. 60, pp. 32-51, 2013.

[44] J. Esarey, T. C. Salmon, and C. Barrilleaux, "What motivates political preferences? Self-interest, ideology, and fairness in a laboratory democracy," Economic Inquiry, vol. 50, no. 3, pp. 604-624, 2012.

[45] R. Durante, L. Putterman, and J. van der Weele, "Preferences for redistribution and perception of fairness: an experimental study," Journal of the European Economic Association, vol. 12, no. 4, pp. 1059-1086, 2014.

[46] R. M. Sheremeta, W. A. Masters, and T. N. Cason, "Winnertake-all and proportional-prize contests: theory and experimental results," Working Paper 12-04, Economic Science Institute Chapman University, 2012.

[47] J. Farrell and M. Rabin, "Cheap talk," Journal of Economic Perspectives, vol. 10, no. 3, pp. 103-118, 1996.

[48] V. Crawford, "A survey of experiments on communication via cheap talk," Journal of Economic Theory, vol. 78, no. 2, pp. 286298, 1998.

[49] R. Croson, T. Boles, and J. K. Murnighan, "Cheap talk in bargaining experiments: lying and threats in ultimatum games," Journal of Economic Behavior and Organization, vol. 51, no. 2, pp. 143-159, 2003.

[50] A. Roth, "Toward a focal-point theory of bargaining," in GameTheoretic Models of Bargaining, A. Roth, Ed., pp. 259-268, Cambridge University Press, Cambridge, UK, 1985.

[51] A. Roth, "Bargaining phenomena and bargaining theory," in Laboratory Experimentation in Economics: Six Points of View, A. Roth, Ed., pp. 14-41, Cambridge University Press, Cambridge, UK, 1987.

[52] R. Forsythe, J. Kennan, and B. Sopher, "An experimental analysis of strikes in bargaining games with one-sided private information," The American Economic Review, vol. 81, no. 1, pp. 253-278, 1991.

[53] M. Shaked and G. J. Shanthikumar, Stochastic Orders and Their Applications, Academic Press, San Diego, Calif, USA, 1994.

[54] J. Nash, “Two-person cooperative games," Econometrica, vol. 21, pp. 128-140, 1953.

[55] A. E. Roth, "Bargaining experiment," in The Handbook of Experimental Economics, J. H. Kagel and A. E. Roth, Eds., Princeton University Press, Princeton, NJ, USA, 1995.

[56] A. Rubinstein, "Perfect equilibrium in a bargaining model," Econometrica, vol. 50, no. 1, pp. 97-109, 1982.

[57] D. P. Baron and J. A. Ferejohn, "Bargaining in legislatures," The American Political Science Review, vol. 83, no. 4, pp. 1181-1206, 1989.

[58] H. Moulin, "Equal or proportional division of a surplus, and other methods," International Journal of Game Theory, vol. 16, no. 3, pp. 161-186, 1987.

[59] L. J. Mirman and Y. Tauman, "Demand compatible equitable cost sharing prices," Mathematics of Operations Research, vol. 7, no. 1, pp. 40-56, 1982.

[60] J. Rawls, A Theory of Justice, Harvard University Press, Cambridge, Mass, USA, 1971.
[61] N. Anbarci and I. Boyd, "Nash demand game and the KalaiSmorodinsky solution," Games and Economic Behavior, vol. 71, no. 1, pp. 14-22, 2011.

[62] U. Fischbacher, "Z-Tree: zurich toolbox for ready-made economic experiments," Experimental Economics, vol. 10, no. 2, pp. 171-178, 2007.

[63] B. Greiner, "The online recruitment system ORSEE 2.0 - a guide for the organization of experiments in economics," Tech. Rep., University of Cologne, Cologne, Germany, 2004.

[64] N. Frohlich and J. A. Oppenheimer, "Choosing justice in experimental democracies with production," The American Political Science Review, vol. 84, no. 2, pp. 461-477, 1990.

[65] L. C. Corchón, "The theory of contests: a survey, Review of Economic Design, vol. 11, no. 2, pp. 69-100, 2007.

[66] E. Dechenaux, D. Kovenock, and R. M. Sheremeta, "A survey of experimental research on contests, all-pay auctions and tournaments," Discussion Paper No. SP II 2012-109, Wissenschaftszentrum fur Sozialforschung, Berlin, Germany, 2012.

[67] C. Harbring and B. Irlenbusch, "An experimental study on tournament design," Labour Economics, vol. 10, no. 4, pp. 443464, 2003.

[68] R. Selten and A. Ockenfels, "An experimental solidarity game," Journal of Economic Behavior and Organization, vol. 34, no. 4, pp. 517-539, 1998.

[69] A. Okada and A. Riedl, "Inefficiency and social exclusion in a coalition formation game: experiment evidence," Games and Economic Behavior, vol. 50, no. 2, pp. 278-311, 2005.

[70] J. K. Goeree and L. Yariv, "An experimental study of collective deliberation," Econometrica, vol. 79, no. 3, pp. 893-921, 2011.

[71] D. Austen-Smith and T. J. Feddersen, "Deliberation, preference uncertainty, and voting rules," American Political Science Review, vol. 100, no. 2, pp. 209-217, 2006.

[72] D. Gerardi and L. Yariv, "Deliberative voting," Journal of Economic Theory, vol. 134, no. 1, pp. 317-338, 2007.

[73] C. F. Karpowitz and T. Mendelberg, "An experimental approach to citizen deliberation," in Cambridge Handbook of Experimental Political Science, J. N. Druckman, D. P. Green, J. H. Kuklinski, and A. Lupia, Eds., pp. 258-272, Cambridge University Press, Cambridge, Mass, USA, 2011. 


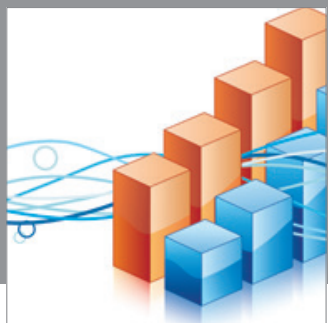

Advances in

Operations Research

mansans

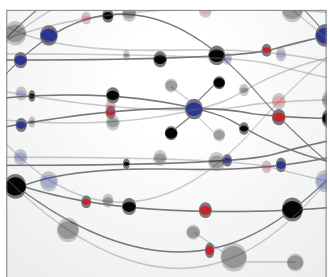

The Scientific World Journal
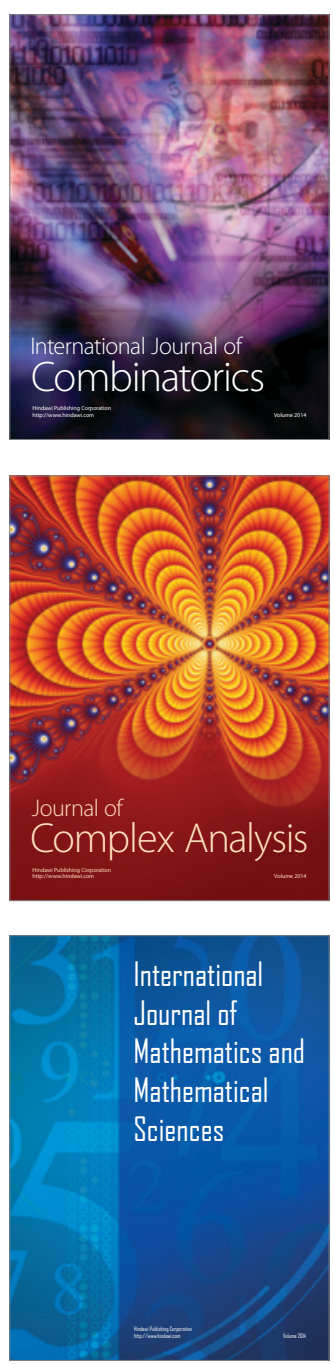
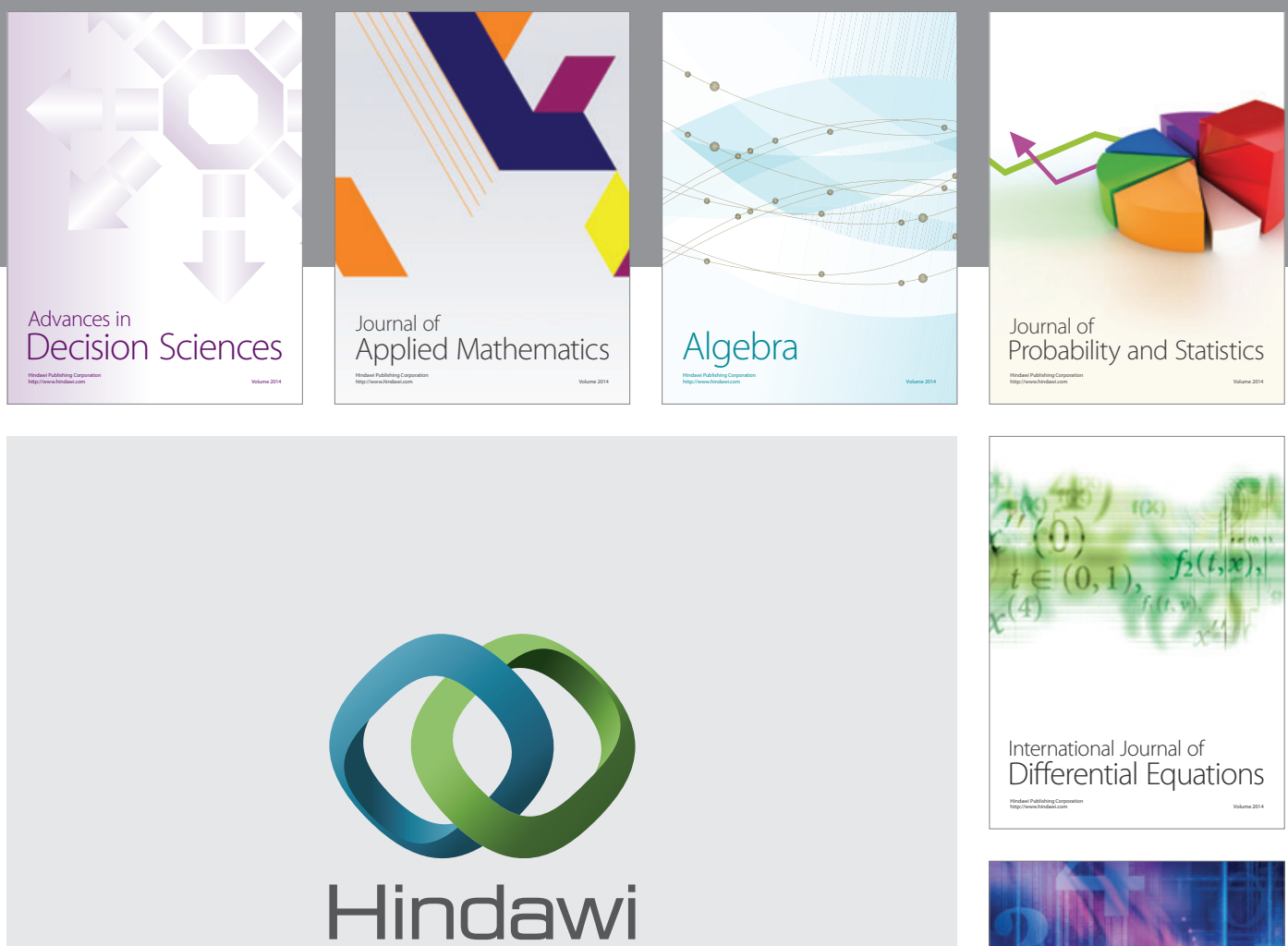

Submit your manuscripts at http://www.hindawi.com
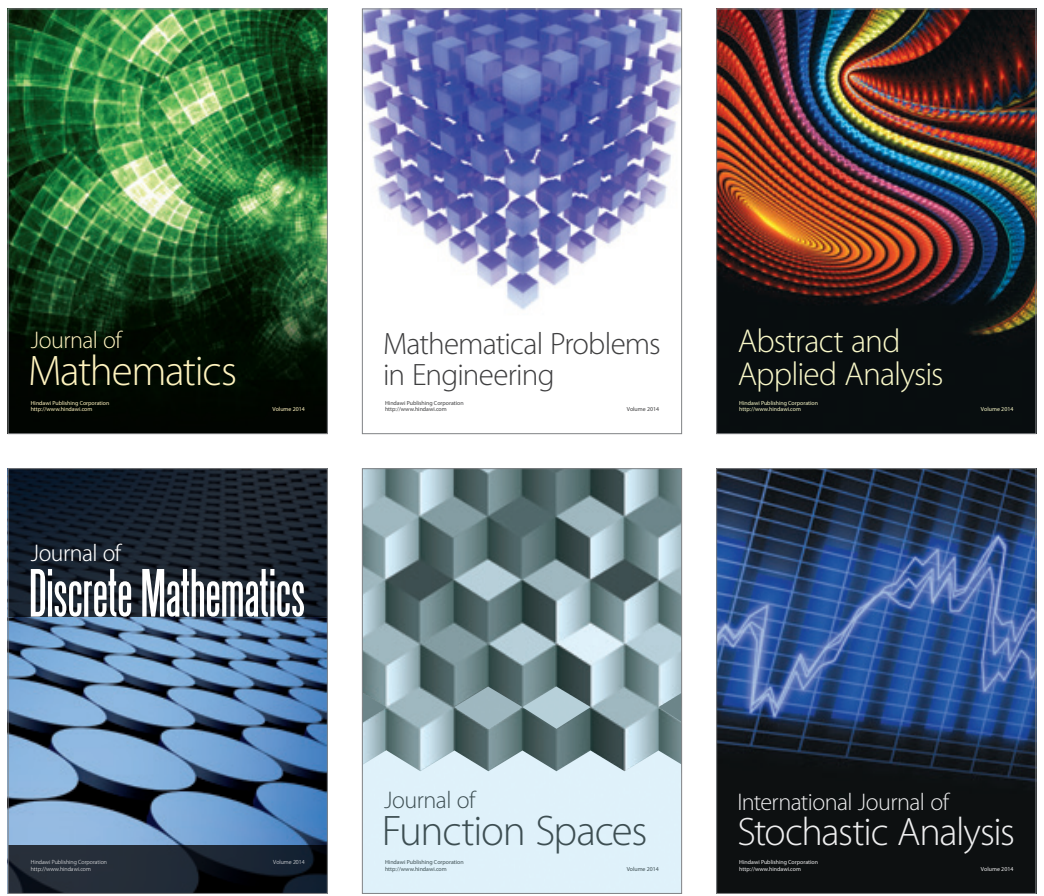

Journal of

Function Spaces

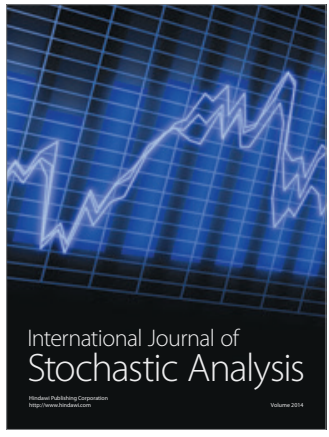

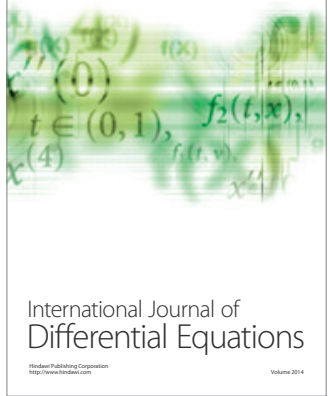
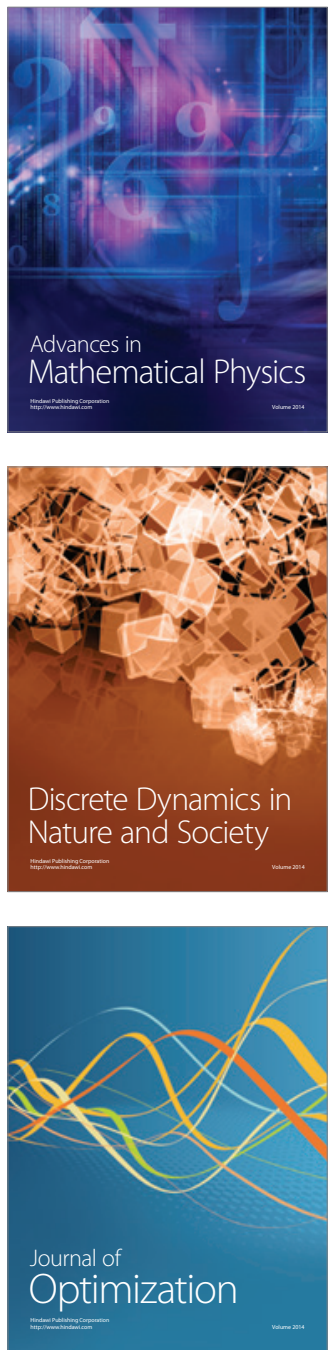